\title{
Contributions of Petri Nets to the Reliability and Availability of an Electrical Power System in a Big European Hospital - A Case Study
}

\author{
CONSTÂNCIO ANTÓNIO PINTO ${ }^{1}$, JOSÉ TORRES FARINHA ${ }^{2}$, SARBJEET SINGH ${ }^{3}$ \\ ${ }^{1}$ Centro de Engenharia Mecânica, Materiais e Processos (CEMMPRE), Universidade de Coimbra, \\ PORTUGAL \\ ${ }^{2}$ Instituto Superior de Engenharia de Coimbra (ISEC), PORTUGAL \\ ${ }^{3}$ LTU, SWEDEN
}

\begin{abstract}
The energy power supply infrastructure of a hospital, to function correctly, needs to be well maintained to ensure its reliability and, by consequence, the maximum integrated availability. In this paper, the authors propose the use of Petri Nets to help the improvement of the electric power system reliability, having as a case study a big European Hospital. The purpose of the research is to identify and analyse the potential failures of the system and to suggest solutions to improve the operations and maintenance to maximise the availability and reliability of those assets through possible and objective answers. It was necessary to develop a diagnosis and planning methodology to assess the reliability of several components of the energy power supply system. It is dynamic modelling based on a block diagram of the system and transposed to representation by Petri Nets. The analysis and the simulation of the discrete events of the system, as well as the visualisation of the process functioning and the communications inside, was made. Additionally, they were referred to other approaches, like the Fuzzy Petri Nets and Stochastic Petri Nets, as well as a future balance about its application in a situation like the analysed in this paper.
\end{abstract}

Keywords: -Maintenance; Reliability; Availability; Petri Nets; Fuzzy Petri Nets; Dynamic modelling. Received: August 3, 2020. Revised: December 1, 2020. Accepted: December 16, 2020. Published: January 6, 2021.

\section{Introduction}

A significant part of the activities of the organisations, particularly those with a large number of Technical Assets, as is the case of hospitals, are related to the maintenance activity. In this case, it not only involves planned maintenance but must also address a large number of problems of failure or reactive maintenance, which also occur regardless of the level of adequate support. This type of difficulties implies a permanent analysis aiming the availability maximisation of the assets at a reasonable cost. The present paper aims to contribute to assure the reliability, the management and operation of the emergency of an electric power system of a hospital unit, using Petri Nets. Based on the significant role played by the power supply system to guarantee the efficient operation of any hospital unit, and due to the current level of requirements for maintenance, the implementation of a maintenance management policy is strategic.

The aims are to establish the sequencing of the risk of failures and to ensure the reliability of the equipment operation, to maximise its availability at reasonable costs.

Additionally, the paper presents a new approach that helps to diagnose and improve the design of the electrical power systems, based on Petri Nets, having as reference a system of a big European hospital.

This paper is organised as follows:

- Section 1 presents the introduction

- Section 2 describes the state of the art

- The Maintenance Concept

- The Electrical Maintenance Activity in a Hospital

- Petri Nets

- Software Tools for System Modelling

- Section 3 characterises the electrical power system in a big European hospital

- Characterisation of the Hospital

- Modelling of the Hospital's Electrical System using Petri Nets

- The Group of Generators and UPS

- Section 4 presents the modelling of the hospital's electrical system by Petri Nets

- Software Simulator Yasper

- Modelling the Hospital's Electrical System Using Petri Nets 


The description of the
Electrical System in the
hospital

- Section 5 corresponds to the discussion about the approach made in the precedent chapters

- Section 6 presents the conclusions and new developments proposed.

\section{State of the Art}

\subsection{The Maintenance concept}

Maintenance is a very important factor for the sustainability of the physical asset's operating functions and, by consequence, their availability and reliability. Maintenance is also a way to mitigate the damages that will occur in assets; therefore, the people in charge must be competent in their professional fields. This paper is based on existing norms and relevant research papers relating to maintenance aiming to support new ideas that may be relevant for further improvement, namely based on the following quotations: The American Hospital Association [1] mentions that proper maintenance of the power system is essential to its safety and reliability; the designer may incorporate certain features into the system to make maintenance safer and more comfortable and to make it possible to perform routine maintenance and inspection without dropping essential hospital load. Anderson \& Neri [2] report that support deals with the specific procedures, tasks, instructions, personnel qualification, and the necessary equipment to satisfy the system maintainability requirement within the real environment use. According to the Department of the Army, TM 5-698-2, [3], maintenance corresponds to the operations and actions that directly retain the appropriate activity of an item or renewing its operation when it is disturbed by failure or some other anomaly - within the context of RCM; it is the necessary process on an object to perform its intended function. Farinha [4] also refers to the norm EN 13306:2010, that defines maintenance as the "combination of all technical, administrative and management actions, during the life cycle of a good, intended to maintain or restore it in a place in which it can perform the required function". Gulati [5] states that maintenance is concerned with keeping an asset in right working conditions, so that the asset may be used for its full productive capacity; the maintenance function includes both upkeep and repairs. Moubray [6] states that the role of maintenance is to ensure that physical assets continue to do what their users want to do. Wang [7] says that maintenance is a function that operates in parallel to production and can have a significant impact on the capacity of the production and quality of the products produced.

Adekitan et al. [8] report that maintenance is a critical and vital operational component that determines vehicle performance and service longevity. Dewi et al. [9] report that maintenance of electrical components in the green building has a more significant correlation or relationship to increase safety performance based on research results, compared to health performance, comfort and convenience. Fatimah and Amin [10] report that the implementation of continuity of optimal hospital building maintenance is expected to reduce the incidence of heavier damage and to minimise the cost of existing repair, ensuring the readiness of supporting facilities for the implementation of health services to the public in the hospital. Indriani et al. [11] report that the development of a green building electrical components maintenance guideline in a web-based information system has shown its capability on improving maintenance work, achieving building reliability requirements. Afzali et al. [12] report that one of the most important ways to improve the reliability of a distribution system is performing maintenance strategies; on the other hand, the studies of cost/benefit will lead to performing the maintenance for the important components. Hoseini et al. [13] report that to achieve reliable and optimised maintenance, the correlation between energy carriers should be taken into account. It deserves continuous improvement and considers that maintenance is a management tool to prevent failures in the physical assets, using both planned and non-planned interventions to maintain their useful lives, in charge of the maintenance engineers.

\subsection{The Electrical Maintenance Activity in a Hospital}

This paper discusses the maintenance and modelling of the electricity system that supplies electricity of a Big European Hospital, as shown in Figures 7 and 9. To analyse the maintenance of the electricity system, they were used norms and papers of other researchers relating to hospitals, to support new ideas that are relevant for further improvement, based on the following quotations: AHA [1] states that the engineering and maintenance department charged with the responsibility for ensuring the safe, cost-effective operation and maintenance of hospital facilities and expensive equipment. Farinha [4] mentions that "another way of analysing the useful 
life was proposed by (AHA, 1996), based on the knowledge of type parameters of most hospital equipment, which allows establishing the maximum limit of maintenance expenses, from the ones it is more economical to replace the equipment than to repair it". Mwanza \& Mbohwa [14] concluded that the maintenance practices in three hospitals were not effective; the conclusion was based on the lack of work order system to capture all work to manage labour, no skill training programs and poor spare inventory and purchasing system. The IEEE C2: National Electrical Safety Code [15] mentions that the purpose of this standard covers basic provisions for safeguarding of people from hazards arising from the installation, action, or maintenance of: (1) conductors and equipment in electric supply stations; and (2) overhead and underground electric supply and communication lines. Christiansen [16] presents a model approach based on over $33,500 \mathrm{~h}$ of measurements within a modern University Medical Centre of Hamburg/Germany to assess the time-dependent course as well as the weekly sum of the demand for electrical energy due to medical laboratory plug loads. According to AHA [1] safety requires adequate provision for the protection of life, property, and continuity of hospital services. The protection of human life is paramount. BenSaleh et al. [17] mention that as there are more and more automated hospitals, the greater protection against the lack of energy is necessary. Hospital systems are increasingly dependent on technology, well-designed emergency energy systems, and the ability to adapt to the changing environments. Jamshidi [18] mentions that Risk-Based Maintenance (RBM) is composed of two main components: (1) A comprehensive framework for prioritisation the critical medical devices; (2) A method for selecting the best maintenance strategy for each device. Risk-based prioritisation of medical devices is valuable to health organisations in the sequencing of maintenance activities and budget allocation for maintenance activities. The WHO (World Health Organization) and Pan American Health Organization [19] mention that promoting "the aims of 'hospitals safe from disasters' by ensuring that all new hospitals aware about the safety will provide them to function in disaster situations and implement mitigation measures to reinforce existing health facilities, particularly those providing primary healthcare". Abdul et al. [20] present a study on equipment inspection and shutdown at optimised risk-based maintenance intervals for a processing facility unit, considering the human errors introduced during these activities.
Ikuzwe et al. [21] mention that the optimal lighting maintenance plan would save up to $59 \%$ of lighting energy consumption with acceptable maintenance costs. Carnero \& Gómez [22] mention that there are no models in the literature analysing the choice of the most suitable maintenance strategy to be applied in electric power distribution systems in Health Care Organizations. Christiansen et al. [23] mention that, in the case of hospitals, this holds particularly for areas directly connected to the diagnosis and medical treatment. Even though the amount of information concerning these loads has increased in recent years, detailed information based on measured data remains scarce. Swain \& De [24] mention that a distribution system connected with smart meters and communication network, capable of monitoring and controlling the individual DERs and loads from a remote location, that can be termed as a smart distribution system. Chan et al. [25] mention that the safety concern and volume of Repair, Maintenance, Alteration and Addition (RMAA) works that have significantly increased in recent years; RMAA works include a variety of work trades. Electrical and Mechanical (E\&M) works are regarded as one of the most hazardous trades with numerous complex activities. Kallambettu \& Viswanathan [26] mention that the functional safety standard IEC 61511 (IEC, 2016) is applied to the Safety Instrumented System (SIS) protection layers to avoid the undesired events or reduce the likelihood of the events or impacts due to failures in the process, process equipment, or its control system including human interactions. García-Sanz-Calcedo et al. [27] mention that the aim of this paper is to analyse the impact of maintenance management on the energy consumption of a hospital in Extremadura (Spain) and to look for existing relationships between the time spent on maintenance operations and the energy consumption of the building. García-SanzCalcedo et al. [28] mention that improving energy efficiency in healthcare buildings is a major challenge in this sector of engineering; however, the energy consumption indicator commonly used in public hospitals ( $\mathrm{kWh}$ per bed) does not take into account the healthcare activity carried out in these buildings. Ismail et al. [29] present a data-driven method for LM using load characteristics and specifications, according to the type of user, time, and location (load behaviour) studies in arranging the loads to occur load balance to improve the load curve around the electrical network during the whole day. Yousefli et al. [30] mention that the complex, uncertain, and dynamic nature of the maintenance management environment is a source 
of concern to facility managers in hospitals due to the unexpected failure of building components, the daily arrival of maintenance orders, and changes in schedule; in such circumstances, centralised systems become far-fetched because of their top-down approach, which lacks a feedback mechanism and ignores new information; therefore, to address any change, centralised systems have to be reformulated, making it impractical, short-sighted, and problematic to adopt them in hospitals. Yuan [31] mentions that the process of continuous development of electrical automation technology, power companies implement state maintenance of relay protection equipment to avoid the drawbacks in traditional maintenance methods to achieve the purpose of extending the service life of relay protection equipment. Poppe et al. [32] mention that Condition-Based Maintenance (CBM) makes use of the actual condition of the component to decide when to maintain and/or to replace the component, thereby maximising the lifetime of the equipment while minimising the number of service interventions. Fatimah \& Amin [10] mention that the implementation of continuity of optimal hospital building maintenance is expected to reduce the incidence of heavier damage and minimise the cost of existing repair and to ensure the readiness of supporting facilities for the implementation of health services to the public in the hospital. Svigelj [33] mentions that with the increasing penetration of distributed energy resources, the smart grids need more and deeper monitoring and control to maintain stable operation; the key is the distribution system state estimation, where the pseudo measurements from AMI are of paramount importance. Sandhu [34] mentions the most suitable power curve model for the analysis of multi-rotor wind turbines; new models have been developed for the energy estimation of a three-rotor wind turbine; simulation results, as presented in the paper, are helpful to decide the best suitable power curve model for single-rotor as well as for multi-rotor wind turbine. Svigelj [35] mentions that the distribution system state estimation is seen as the key technology for providing the full observability of the distribution grid. The most important input parameters into distribution system state estimation are topology parameters, phasor measurements and pseudo measurements.

\subsection{Petri Nets}

Petri nets can be identified as certain types of bipartite directed graphs that consist of three basic types of objects. These objects consist of places, transitions and directional arcs that connect places to transitions and transitions to places.

In graphical representation the place is represented by round or oval circles, where tokens deposit or pass by only as needed, transitions are represented by bars or boxes, where they can be fired to move the tokens to another place, (transitions, because the tokens cannot be deposited there, just pass).

In their simplest form, Petri nets can be represented by transitions, along with their entry and exit locations. This basic network can be used to represent various aspects of the system being modelled. To study the dynamic behaviour of the system being modelled, in terms of conditions and changes, each location has the potential to store none or a positive number of tokens, represented by small solid points. The presence or absence of a token in a place can indicate whether a condition associated with this place is true or false.

Petri net can be defined as follows: it consists of 5tuples $\mathrm{N}=(\mathrm{P}, \mathrm{T}, 1,0, \mathrm{Mo})$, where

1) $P=\{P 1, P 2, \ldots, P m\}$ is a limited set of places;

2) $\mathrm{T}=\{\mathrm{t} 1, \mathrm{t} 2, \ldots, \mathrm{tn}\}$ are a limited set of transitions, $\mathrm{P} \mathrm{U} \mathrm{T} \neq \varnothing$, and $\mathrm{P} \cap \mathrm{T}=\varnothing$;

3) $\mathrm{I}(\mathrm{P}, \mathrm{T}) \rightarrow \mathrm{N}$ is an Input function that defines an arc directed from a Place to a Transition, where $\mathrm{N}$ is a set of negative integers;

4) $\mathrm{O}(\mathrm{T}, \mathrm{P}) \rightarrow \mathrm{N}$ is the Output function that defines the arc directed from Transition to Place; and

5) Mo: $\mathrm{P} \rightarrow \mathrm{N}$ is the initial marking.

Marking is the assignment of tokens to place the Petri net. Tokens are primitive concepts for Petri nets (such as places and transitions). Tokens are assigned to and can be located in Petri net sites. The number and position of tokens may change during the implementation of the Petri network. The token is used to determine the execution of the Petri network.

A simulation example is presented in Figure 1, where the Petri net has represented as follows:

$$
\begin{aligned}
& \mathrm{P}=\{\mathrm{p} 1, \mathrm{p} 2, \ldots, \mathrm{p} 7\} ; \\
& \mathrm{T}=\{\mathrm{t} 1, \mathrm{t} 2, \ldots, \mathrm{t} 5\} ; \\
& \mathrm{I}(\mathrm{t} 1, \mathrm{p} 1)=2, \mathrm{I}(\mathrm{t} 1, \mathrm{pi})=0 \text { for } \mathrm{i}=2,3, \ldots, 7 \text {; } \\
& \mathrm{I}(\mathrm{t} 2, \mathrm{p} 2)=1, \mathrm{I}(\mathrm{t} 2, \mathrm{p} 7)=1, \mathrm{I}(\mathrm{t} 2, \mathrm{pi})=0 \text { for } \mathrm{i} \\
& =1,3,4,5,6 \text {; } \\
& \mathrm{O}(\mathrm{t} 1, \mathrm{p} 2)=1, \mathrm{O}(\mathrm{t} 1, \mathrm{p} 3)=2, \mathrm{O}(\mathrm{t} 1, \mathrm{pi})=0 \text { for } \\
& \mathrm{i}=1,4,5,6,7 \text {; } \\
& \mathrm{O}(\mathrm{t} 2, \mathrm{p} 4)=1, \mathrm{O}(\mathrm{t} 2, \mathrm{pi})=0 \text { for } \mathrm{i}= \\
& 1,2,3,5,6,7 \\
& \mathrm{Mo}=\left(\begin{array}{lllllll}
2 & 0 & 0 & 0 & 0 & 0 & 1
\end{array}\right)
\end{aligned}
$$




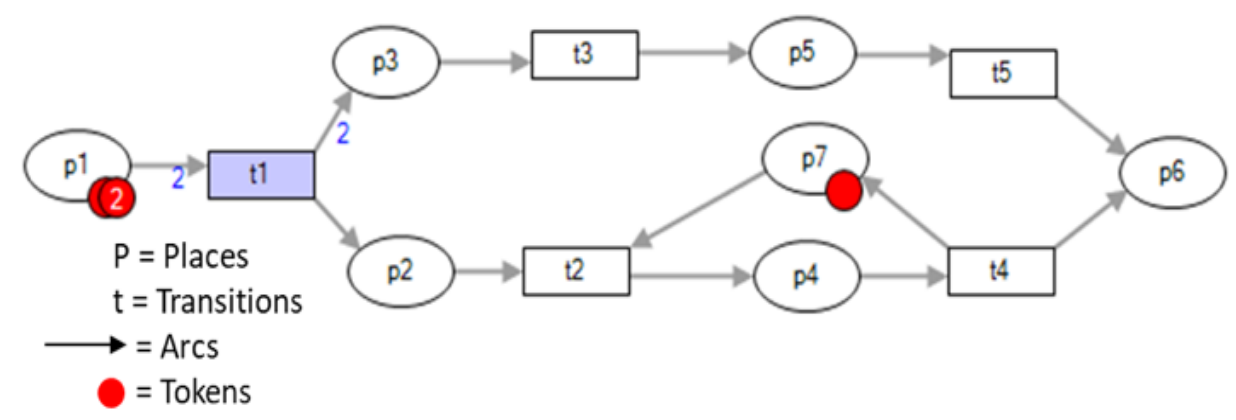

Fig. 1. Petri Nets simulation circuit as an example, using $\mathrm{HiPS}^{l}$ software.

${ }^{1}$ https://sourceforge.net/projects/hips-tools/ 
Based on Petri Nets, the authors use this approach to evaluate an electrical system, in a large hospital, that supports its daily activities. This critical asset requires very good maintenance to avoid failures which could result in disruption of the hospital activities that are considered very risky. Therefore, the problem of maintenance plays an important role in this regard; so, it requires special expertise in order to know the historical data of failures in the complicated electrical circuit of the hospital. But, if the historical data is not available because the operators are neglected to collect it, or there is not an information system to manage them, it is very difficult to do the maintenance work. Due to the unavailability of historical data and technical work drawings, it is very difficult to conduct a research and convincing investigation. From this difficulty, it cames the idea of solving it using a very powerful tool, namely Petri Nets. With circuits and simulations, Petri nets can navigate the electrical system circuit easily, because it uses a tokens flow that represents an electric current. Places as items or components and transitions as an operating system or components that supply tokens to flow from part to part, in order to identify and categorise successive instruments which are more critical, less critical and subsequently. Performance evaluation plays an important role in planning, design, and operating dynamic discrete event systems. Petri Nets is a modelling tool that provides graphical representations of dynamic and complex systems, based on a strong mathematical basis, being disseminated both by the publication of many research results published in the last decade and by various performance domains such as communication networks, production systems, automation, traffic, logistics, the order of care, fault diagnosis and, in general, all discrete event systems. According to Wang [36], Petri nets were named after Carl Petri has defined a general-purpose mathematical tool for describing relations existing between conditions and events. This work was done in the years 1960-1962. Since then, Petri nets have resulted in considerable research due to the fact that they can be used to model properties such as process synchronisation, asynchronous events, sequential operations, concurrent operations, and conflicts or resource sharing. These properties characterise Discrete Event Dynamic Systems (DEDS). This, and other factors, make Petri nets a promising tool and technology for the application of various types of DEDS. As a graphical tool, Petri nets provide a powerful communication medium between the user, typically requirements engineer, and the customer. Complex requirements specifications, instead of using ambiguous textual descriptions or mathematical notation that are difficult to understand by the customer, can be represented graphically using Petri nets. This, combined with the existence of computer tools, allows interactive graphical simulation of Petri nets, puts on hands the development engineers a powerful tool to assist in the development process of complex engineering systems. The graphical representation also makes Petri nets intuitively very appealing. They are extremely easy to understand and grasp - even for people who are not very familiar with the details of Petri nets. This is because Petri net diagrams resemble many of the drawings which designers and engineers make while they construct and analyse a system. Volovoi [37] deals with the dynamic modelling of degrading and repairable complex systems as modularity allows a focus on the needs of a system reliability modelling and tailoring of the modelling formalism accordingly. Chew et al. [38] mention that Petri Nets provide a logical, easily understood and compelling way of predicting the reliability of a system or platform. Garg [39] mentions that Petri Nets tool is applied to represent the asynchronous and concurrent processing of the order instead of the fault tree analysis. Leigh \& Dunnett [40] mention that the study has aimed to develop a model using Petri Nets to determine the feasibility of adopting this technique to model the maintenance processes efficiently. Ren et al. [41] mention that if a Petri Nets are required to model processes that have a random (or pseudorandom) nature and, if this randomness follows a specific pattern such as a statistical distribution, the transitions can sample their switching times from this distribution. Sadou et al. [42] mention that this new representation of the Petri net with formulae of linear logic allows us to define the notion of scenario formally; to obtain a minimal situation, they must be considered three elements: (i) the order of events governed by a useful relation of cause and effect in the system; (ii) the list of activities of the scenario must be minimal (i.e. without loop events); and (iii) the final marking corresponding to the feared state must be minimal. Sheng \& Prescott [43] mention that a variety of CPN (Coloured Petri Nets) models are established to represent fleet maintenance activities and maintenance management, as well as the factors that have a significant impact on fleet maintenance including fleet operation, aircraft failure logic and component failure processes. Baidada et al. [44] mention that this approach consists of generating and collecting the corresponding traces of different cases, filtering and analysing them using Colored Petri Nets to 
extract a high-level sequence diagram finally. Xie et al. [45] mention that a novel energy consumption model based on Generalised Stochastic Petri Nets is proposed, and an analysis method is also presented; furthermore, the model was successfully applied to a turning machine tool. Lee \& Mitici [46] propose a formal framework to assess the safety and efficiency of maintenance strategies using agent-based modelling, stochastically and dynamically Coloured Petri Nets, and Monte Carlo simulation; the authors model an end-to-end aircraft maintenance process, considering several maintenance stakeholders. Kabir \& Papadopoulos [47] mention that Petri Nets are another formal graphical and mathematical tool capable of modelling and analysing dynamic behaviour of systems. They are also increasingly used for system safety, reliability and risk evaluation. Caterino et al. [48] present a new assessment method, also adapted to a specific risk, such as the mechanical one, using as assessment tools the check-list and Petri Nets. Eisenberger \& Fink [49] mention that several types of Petri nets with different properties have been introduced. One of the recently proposed extensions of Petri nets is the Abridged Petri Nets (APN) which fulfil the specific requirements of railway rolling stock maintenance. Taleb-Berrouane et al. [50] mention that Petri Nets are a mathematical tool that has been applied for maintenance modelling and simulations of different applications. Zhou \& Reniers [51] mention that Weighted Fuzzy Petri Nets (WFPN) with inhibitor arcs are proposed to model relationships between risk factors and risk assessment structure, considering veto factors. Fierro et al. [52] mention techniques that include Colored Petri Nets, which have been effectively tested in hierarchical modelling, analysis and control of distributed systems, characteristics suitable for the specification of a supply chain management system in an industry 4.0 scenario. Elusakin Shafiee [53] present an advanced analysis method using Stochastic Petri Nets (SPN) to estimate the reliability of subsea BOP systems subject to Condition-Based Maintenance (CBM) with different failure modes. Liu et al. [54] mention that the coloured Petri Net is applied for an integrated description of independent information classification, aiming at risk identification and risk management framework; according to the quality deterioration tendency, the risk grades management and decision-making system are established. Sheng \& Prescott [55] present a novel Hierarchical Coloured Petri Net (HCPN) model of a fleet spare inventory system, which accounts for these issues alongside the fleet deployment and mission-oriented operation; the application of the model is demonstrated using case studies based on two example fleets. Singh \& Singh [56] mention a technique to make the performance analysis of safety-critical and control systems that helps to estimate the risk and the performability to ensure the system dependability requirements. Farinha [57] shows an example using Petri Nets on an electrical power system: an Emergency Generator that, as is known, starts operating when the external mains voltage from below a certain value about the nominal voltage. In the example, the value assumed for starting the Emergency Generator is $350 \mathrm{~V}$, that is, when the value of the voltage of the external electrical network from below this value the Generator starts, turning off when the value of the electrical network is above that. For this purpose, the following situations are assumed for the Emergency Generator: The Generator can be in two possible operational states: in standby and operation (generating electricity); two situations give rise to those states: mains voltage above $350 \mathrm{~V}(>350 \mathrm{~V})$ and below this value $(<350 \mathrm{~V})$; other possible states, such as malfunction, are not considered. Figure 2 illustrates the state diagram and the Petri nets for the preceding situations, respectively".

Petri nets can also be used in a complementary way to the preceding, as is described by Solaiman et al. [58] that proposed a "method to improve fault prognosis using Fuzzy Petri Nets (FPN), by adding internal and external changing conditions to the prognosis process"; the authors introduce new kinds of certain factors that can be adapted with changed conditions on a bus of the reliability test system to show its differences from traditional FPN. 


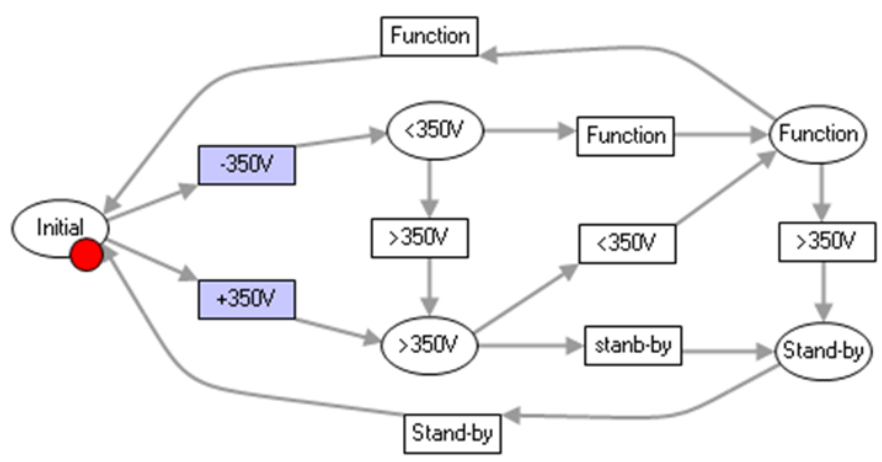

Fig. 2. Example of Petri net remains on standby, (red dot $=$ token $=$ energy of electrical power $)$.

\subsection{Software Tools for System Modelling}

The software used for system modelling is Yasper, a tool to specify and execute models of discrete-step processes. A Yasper model shows the steps of a process and the order dependencies between them in one or more diagrams. The diagram technique supports alternative and parallel paths, repetitions of steps, and contention for resources between steps. The diagram isn't merely a sketch, but provides an exact formal specification of the order dependencies; this allows simulation. Yasper is a software to be supported by tools that use XOR semantic elements, time calculations, Petri Stochastic Nets, Petri Nets with Time, Graphical Editor, Game Token Animations, Fast Simulation, Clean Reduction, Simple Performance Analysis, Change File Format and different workflow cases that can run in MS Windows. Discrete process modelling tools, in general, tend to support techniques such as state machines, flowcharts, and activity diagrams, which are very closely related to Yasper models (Figure 3).

http://www.yasper.org/ [59] refer that Yasper $^{2}$ is a tool for modelling and simulating stepwise processes; it is intended to be used for business process analysis and redesign, software requirements analysis and high-level software architecture design. Yasper intentionally limits itself to model the order dependencies in structures and stepwise processes, including issues of cooperation and resource contention, with some support for performance analysis; it is not intended for modelling other aspects of systems, such as data processing, organisation structure and user interface design. Yasper models rely on an exact definition of how processes can execute, even in the presence of concurrency, cooperation, and resource contention between processes. This makes possible more exact designs: the errors can be spotted through

\footnotetext{
${ }^{2}$ http://www.yasper.org/
}

simulation, symbolic execution of the model; this is achieved by defining processes in terms of Petri nets. Yasper extends Petri nets with notions such as subprocesses, decision blocks, inhibitor and resets connections, and roles. Yasper is particularly suited for the modelling of workflows: processes with well-designated start and endpoints. Unique to Yasper is how it distinguishes between different workflow cases in a process. Since Yasper models have an exact execution semantics, simulation is a very powerful technique, both in model debugging and in the actual process analysis. Yasper supports two modes of simulation: manual mode, in which the user selects the subsequent steps to execute by clicking in the diagram; and an automatic mode, which randomises the choice of steps and produces an aggregated report with relevant statistics. Yasper was written to provide modelling convenience, rather than new and unique new modelling features: the features it supports are well known, well analysed, existing support for them in other tools, in particular, the colored Petri net-tools (such as ExSpecT), CPN Tools, and ReNeW. Additionally, these tools can express many things that Yasper does not support. What Yasper aims to do is to make modelling and simulation easier to perform and to learn, especially for workflows. Yasper models can emulate techniques such as state machines, flowcharts, and activity diagrams.

Hee et al. [60] mention that Yasper's simulation is specifically designed for workflow nets: Petri nets that take individual cases from a given initial point to a given final point. Business processes and workflows typically have this structure. The simulation report indicates completion of cases and offers standard performance indicators. Sulaiman et al. [61] mention that Yasper is a tool for modelling and simulating stepwise process; the authors use an extended Petri net as its modelling technique. Yasper offers easy editing, token gameplay and performance analysis with randomised automatic 
simulation for basic Place/Transition nets with some extension, including case-specific versus inter-case token flow, reset and inhibitor arcs, and decision nodes with parameterised probabilities of alternatives, etc.

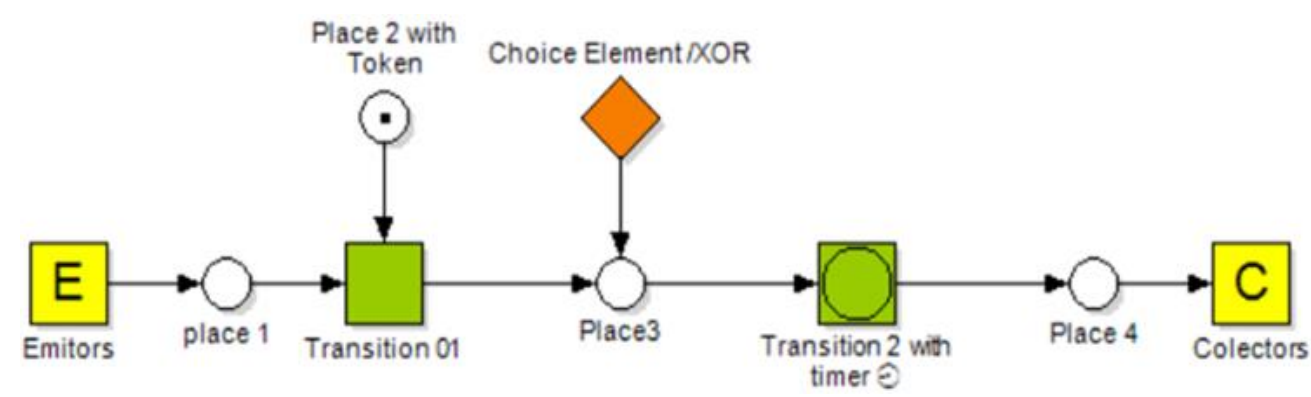

Fig. 3. Shows the definitions tools in the Yasper System and the arrows are named Arcs.

In the Yasper simulator software, Emitter and XOR can distribute tokens as an input to the work system

\section{Electrical Power System of a Big European Hospital}

\subsection{Characterisation of the Hospital}

A new Pediatric Hospital of a European Country is a medical care building where people take care of their children. It was started in 2005 and got accreditation from the National Health Care Agency in 2010. The hospital is about six hectares; the unit has a total construction area of $90.000 \mathrm{~m}^{2}$, consisting of the following constructions: Main building consisting of 21 structural bodies, where all health care services are installed. Designated by Building A, it has 14 levels of distinct pavements, located between the floor seven and floor four (roofing); Support building, of facilities and equipment services, warehouses, workshops and thermal power plants, is designated by building B. This research focus on Emergency Power Supply System (EPSS) installation in the hospital. The leading equipment in this system is fed by the public electric power supplier with two inputs. It also has three units of 1000KVA generators, two units of UPS (Uninterrupted Power Supply) with 300KVA, 1 unit of UPS of $8 \mathrm{KVA}, 20$ units of UPS of 20KVA, in addition to tokens inputted on demand from the circuit (Figure 3).

1 unit of ATS (Automatic Transfer switch), three transformer units, 2 PT (Power Transfer), 3 LVDB (Low Voltage Distribution Board) input units, 6 LVDB central output units and other peripheral instruments (Correction Battery, LV Distribution Network, Indoor Lighting (Normal/Emergency), Output and Obstruction Signalling, Normal/Emergency Outlets), and Ground Network. With this system characterisation, we will use the Petri Net Time methods to analyse and diagnosis the operation and efficiency of the power system efficiency, in terms of reliability and maintenance context.

\subsection{Modelling of the Hospital's Electrical System Using Petri Nets}

The main contribution of the Petri Nets system is to simulate and analyse complex systems, which can start with: Asset system observation and identification; Asset system definition and analysis; Asset system Modelling; Asset system simulation and evaluation; Determination of research results of the Asset system (Figure 4).

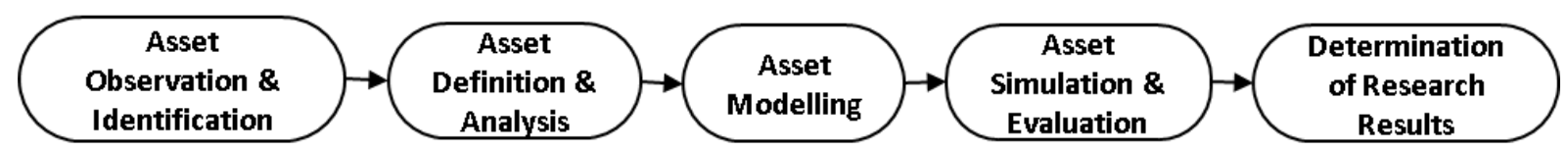

Fig. 4. Research sequence Block diagram.

For clear and easy modelling by Petri nets of an Asset system with complex circuits, it can be started according to the following method: Asset Hierarchy Block Diagram (AHBD); Asset Functional Block 
Diagram (AFBD); Asset Process Flow Diagram (APFD); and Asset Petri Net Modelling. The Asset Hierarchy Block diagram, shown in Figure 5, illustrates the maintenance reliability system, which is recommended by the Reliability Centred Maintenance (RCM) standard, created to facilitate the flow of institutional system management; so, it can be clearly seen which part will be carried out and who is responsible for that part, does not have overlapping responsibility and easily arranged as a good work team.

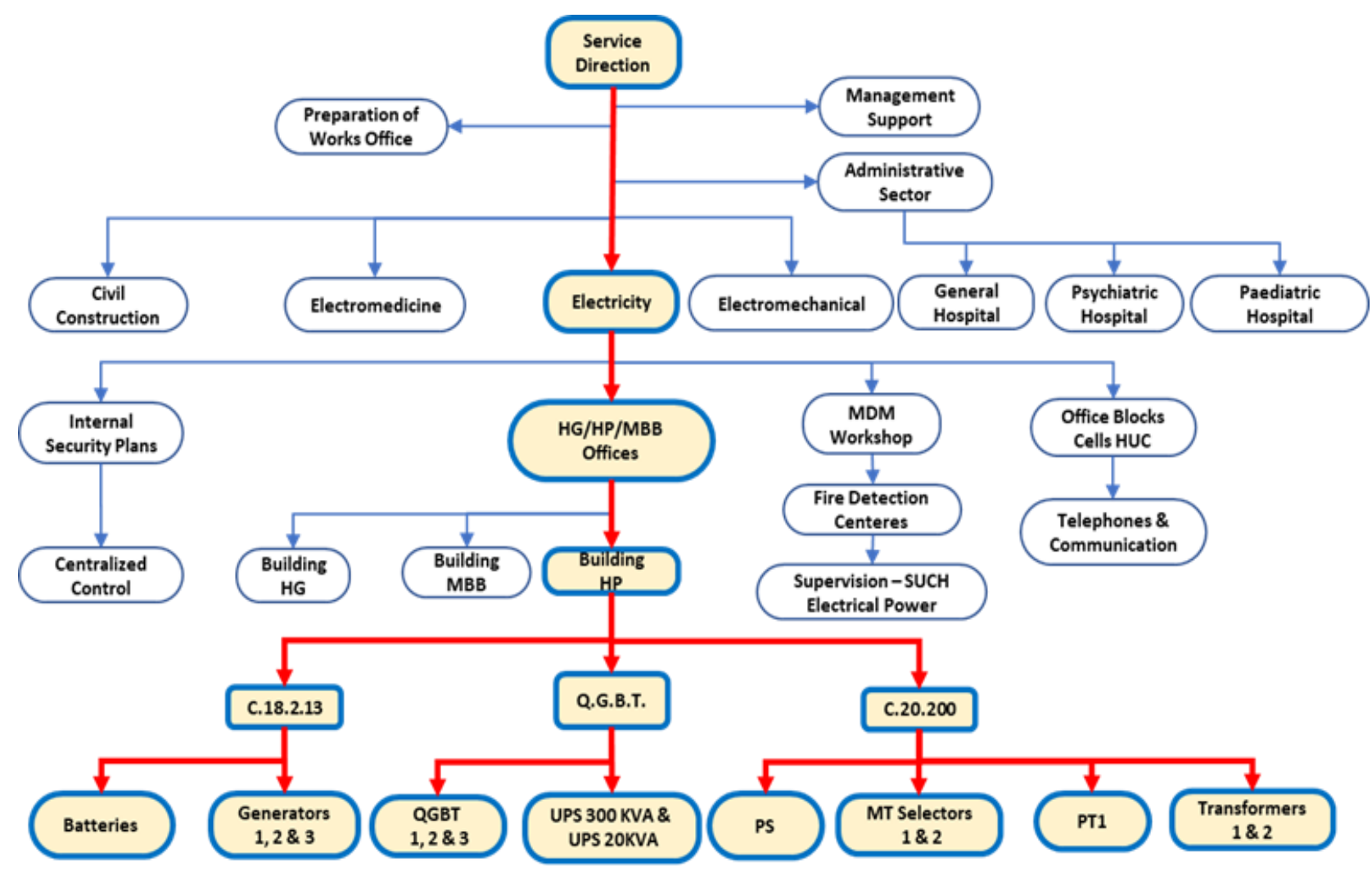

Fig. 5. Asset Hierarchy Block Diagram (AHBD), Facilities and Equipment Services.

Figure 6 shows synthetically how the hospital system works: The main entrance of public electricity, which supports the entire hospital system; Input from two power generators, each with $1000 \mathrm{kVA}$ to feed critical units; Input from one power generator, with $1000 \mathrm{kVA}$ for non-critical units; and Output for end-users in all hospitals, both critical and non-critical. With the information from the functional block diagram of the asset, the management plan is better defined according to the standards required by the hospital.

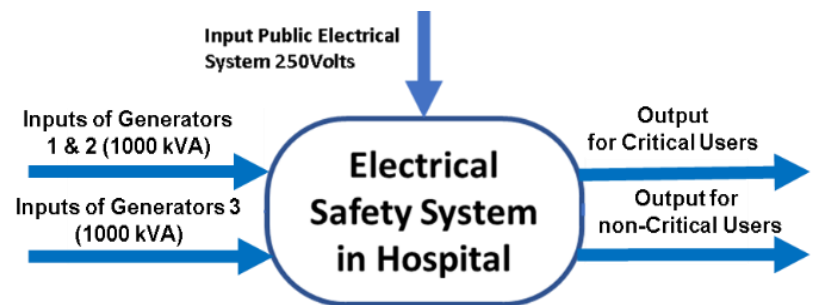

Fig. 6. Asset Functional Block Diagram (AFBD).

Figure 7 shows the process block flow diagram in Assets, which is modelled using a block diagram to make it more clearly visible to stakeholders, to know how the electric current flows in the circuit. 


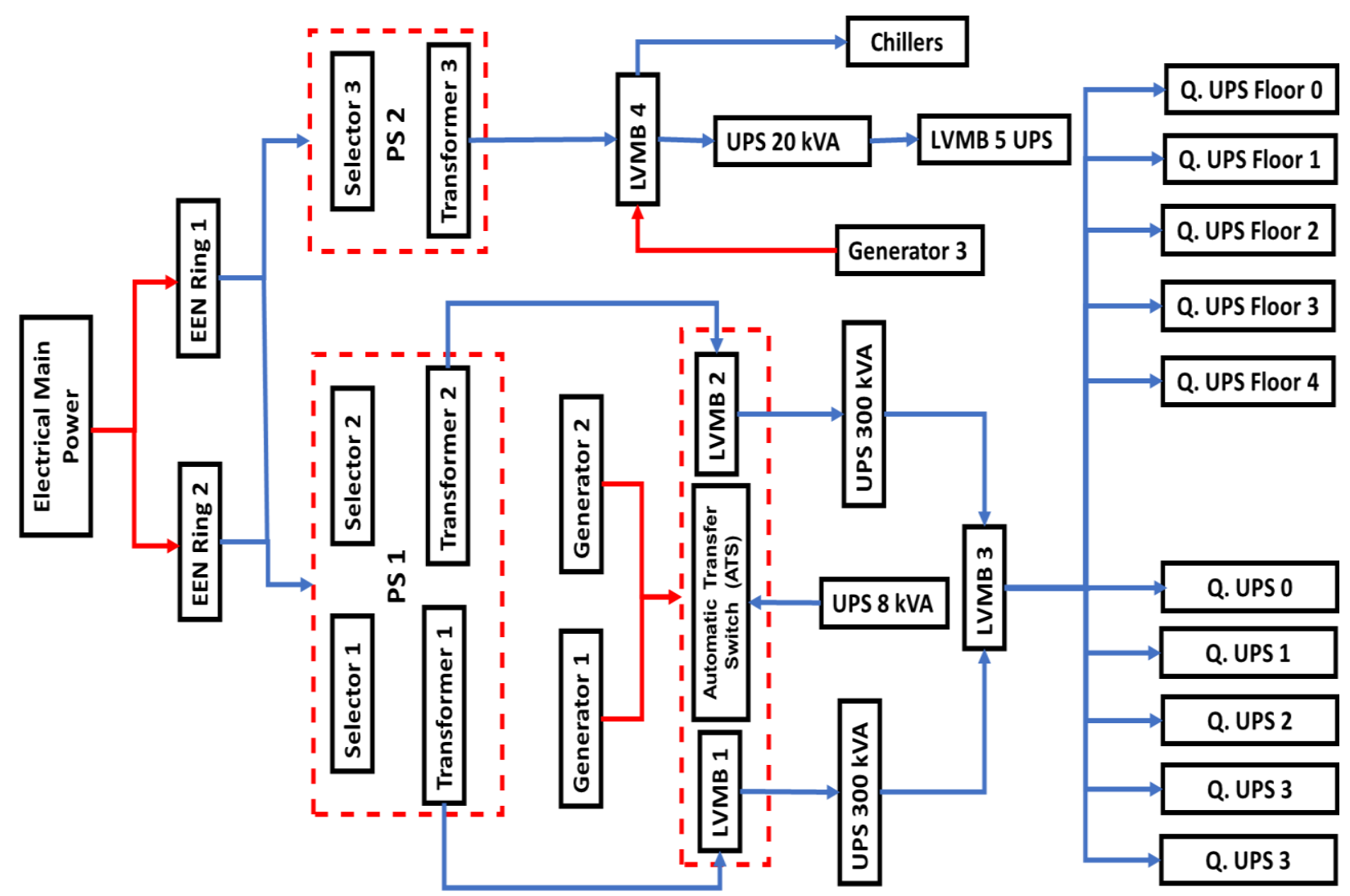

Fig. 7. Asset Process Flow Diagram (APFD).

Based on the block diagram in Figure 5 or 7 , the assets can be modelled using Petri net, as shown in Figure 8, using the Yasper simulator software with no tokens (only showing an image of the system of assets).

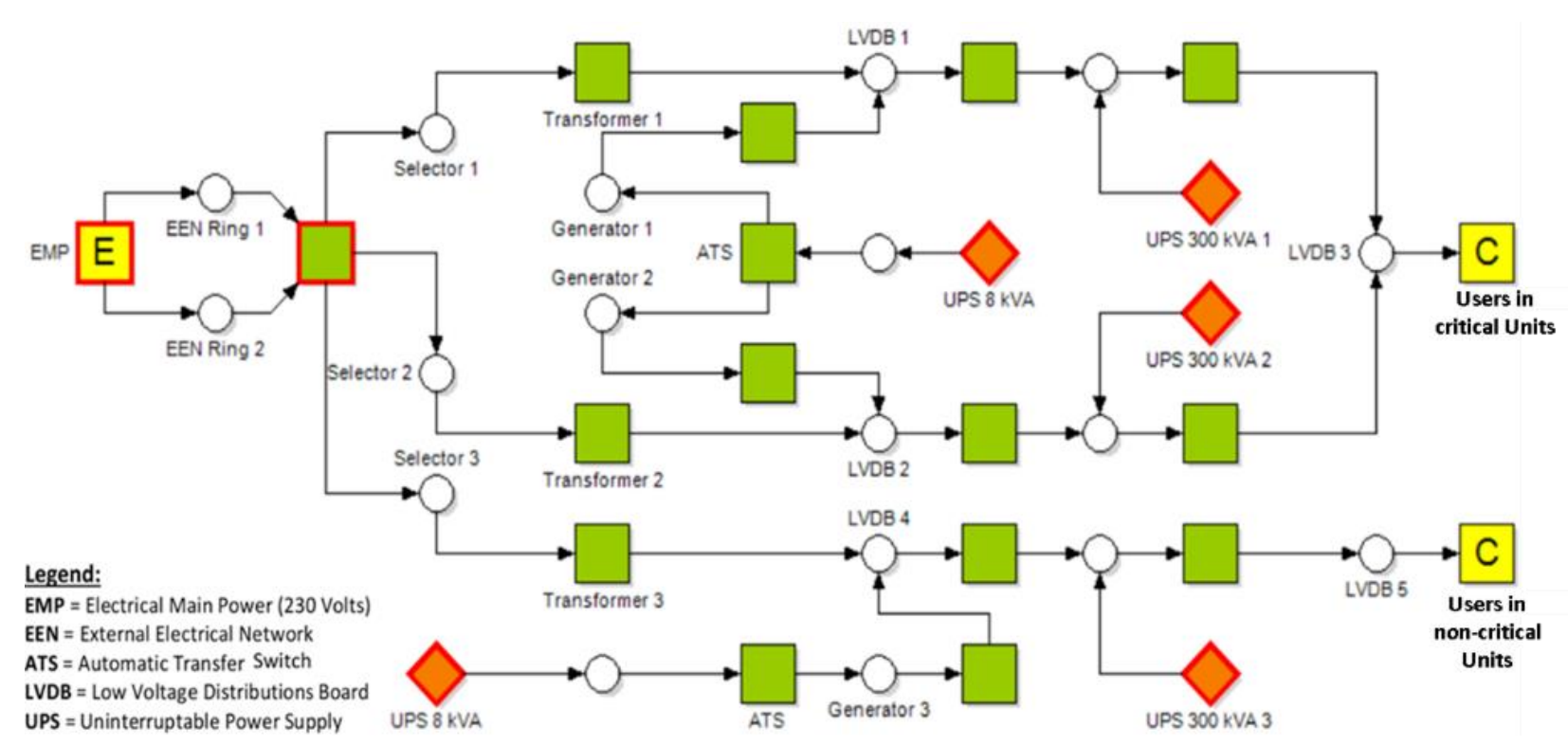

Fig. 8. Asset process Petri Net Modelling.

\subsection{The Group of Generators and UPS}

The power system includes UPS (that ensure part of the hospital's operation, in case of power failure provided by the external energy supplier). The hospital also is equipped with three generators, two of $1000 \mathrm{kVA}$ and one of 
$500 \mathrm{kVA}$, powered by Diesel internal combustion engines. The command and transfer board of the most powerful power groups has also installed a synchronisation system between the two groups since they can operate in parallel after synchronisation between them, as shown in Figure 9.

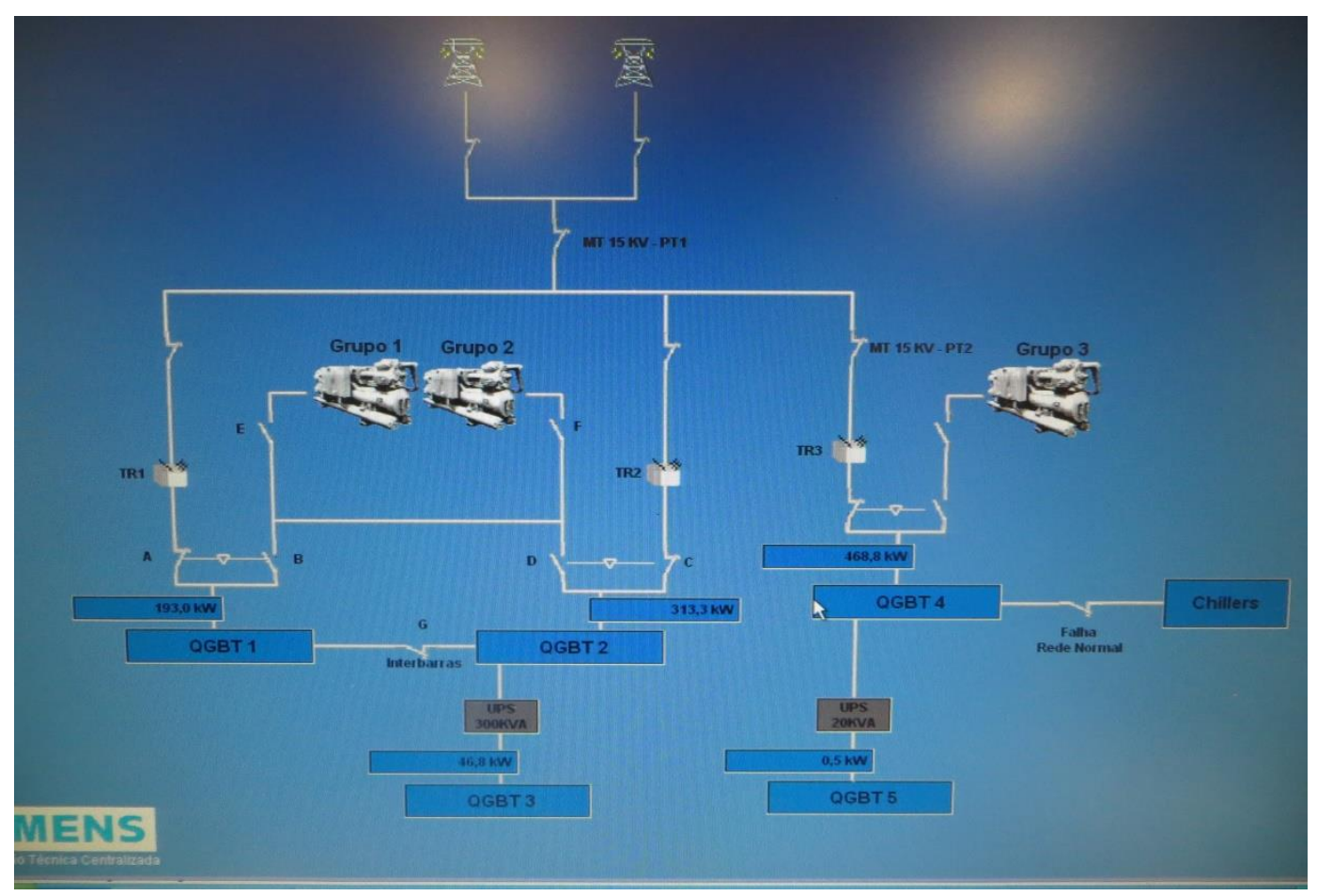

Fig. 9. Electric Power System circuit diagram in the hospital.

\section{Modelling the Hospital's Electrical System Using Petri Nets}

\subsection{Software Simulator Yasper}

Petri nets are, traditionally, divided into low-level Petri nets and high-level Petri nets. One of the Yasper software belongs to the class of high-level Petri nets that are characterised by the combination of Petri nets with programming languages. The high-level Petri nets aim at their real implementation, namely because they allow the construction of compact and parameterised models. The Yasper software simulations allow to investigate different scenarios and explore system behaviour interactively or automatically: An interactive simulation is similar by debugging in a single step, providing a way to "walk" through a Yasper software model, evaluating different scenarios in detail, and verifying that the model works as expected. During an interactive simulation, the modeller is responsible for the next step, and determines the next level, selecting between enabled events in the current state. Automatic simulation is similar to program execution, and proposes running the Yasper software model as quickly and efficiently as possible without human interaction and inspection; automated simulation is, typically, used for performance testing and analysis. Yasper software networks include a time concept that captures the time spent by events in the system.

Differences between high-level Petri nets and lowlevel Petri nets are: According to Jensen [62], Highlevel Petri nets are now widely used in both theoretical analysis and practical modelling of concurrent systems. The main reason for the success of this class of net models is that they make possible to obtain much more succinct and manageable descriptions than can be obtained by means of lowlevel Petri nets, while, on the other hand, they still offer a wide range of analysis methods and tools. The step from low-level nets to high-level nets can be compared to the step from assembly languages to modem programming languages with an elaborated type concept. In low-level nets, there is only one kind of token, and this means that the state of a place is described by an integer (and, in many cases, even by a Boolean value). In high-level nets, each token can carry complex information which, e.g., may describe the entire state of a process or a database. Today, most practical applications of Petri 
nets use one of the different kinds of high-level nets. A considerable body of knowledge exists about high-level Petri nets; this includes theoretical foundations, analysis methods and many applications.

\subsection{Modelling the Hospital's Electrical Sys- tem Using Petri Nets}

One objective of the research that supports this paper is to analyse the dynamics of the hospital power system and, particularly, its weaknesses. A Petri net model can adequately represent this type of behaviour.

Figure 10 illustrates the Petri Nets implementation using Yasper software program to simulate the electric power supply diagram of the hospital under consideration, as shown in Figure 9.

Figure 10, regarding the Petri nets circuit, shows the primary current from the Electric Main Power (EMP) 380 Volt that enters through the External
Electric Network (EEN 1 and 2); then, it goes to selector 1,2, and 3; from the selector, it continues to transformers 1, 2, and 3; the electrical current continues to Low Voltage Distribution Board (LVDB) 1, 2 and 4, forwarded to UPS 1, 2, and 3; then, it goes to LVDB 3 and 5 and, finally, to the user, that is the hospital in regular operation.

The Petri Net circuit, in some transitions, have a time set; then, there are changes that fire out tokens from the generators, within the time when the UPS runs out of energy, that is between 15 and 30 seconds. The contributions use Petri Nets to define and analyse this situation to find out which are the essential critical items or modules of the system. In this way, we can easily identify the physical assets where a specific maintenance policy must be applied to guarantee the reliability and availability conditions and to mitigate failures; usually, a condition maintenance policy with prediction is the best option.

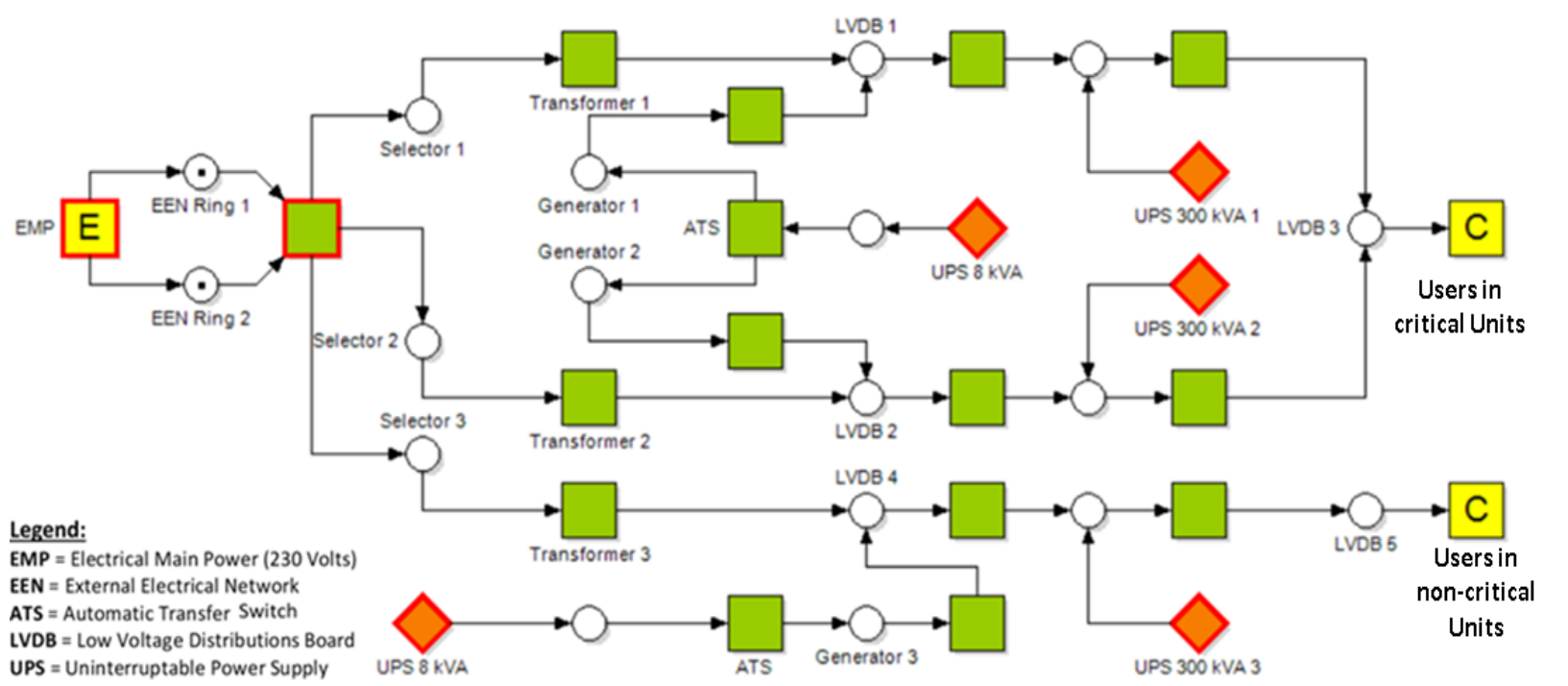

Fig.10. Modelling and simulation with PETRI NETS of the electric power system, where the token represents the electric current from the Electrical Main Power (EMB) to the EEN Ring 1 and 2 positions in the circuit, just an illustration on the system. 


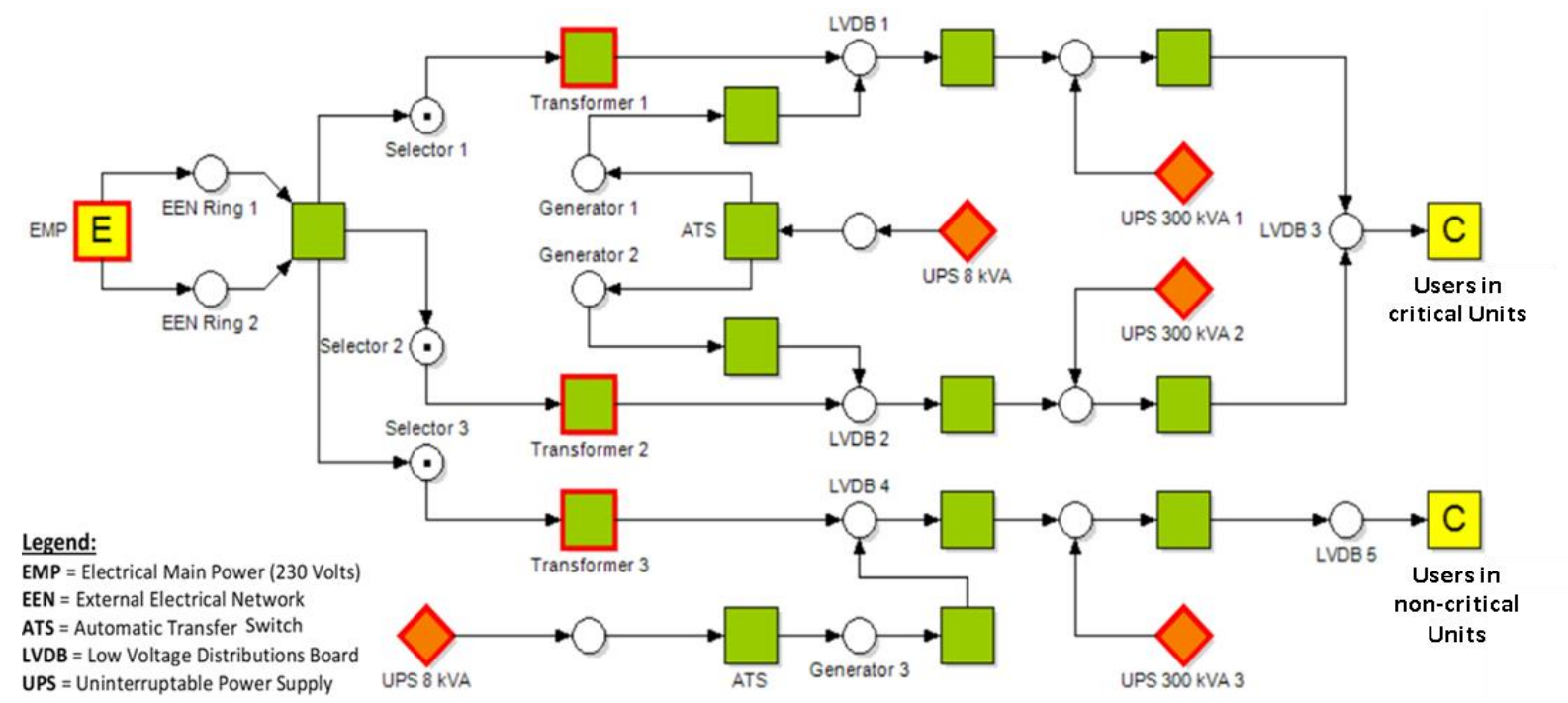

Fig. 11. The situation with tokens represents the electric current that goes to the position of selector 1, 2 and 3 continues to move until the user.

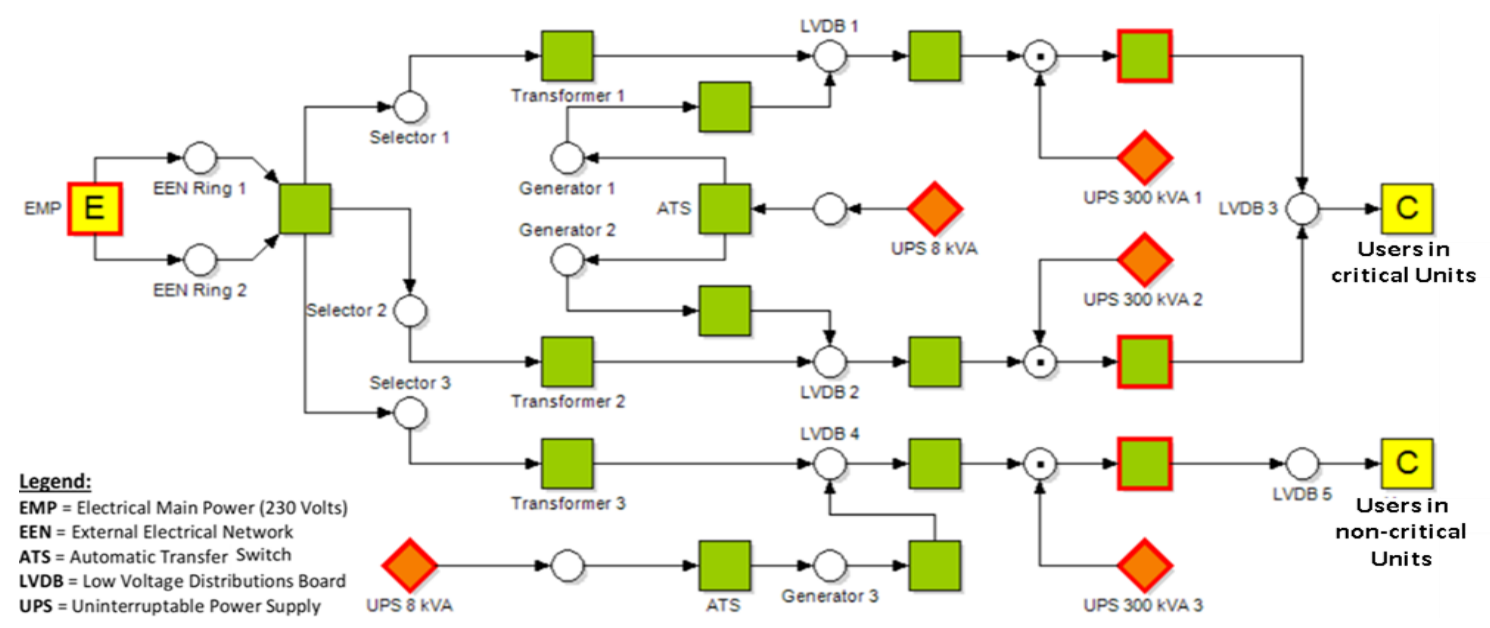

Fig. 12. The situation is that the token represents the electric current stored in UPS 1, 2 and 3 with 300KVA active, which means UPS 1, 2 and 3 with 300KVA functions as a replacement for non-functioning 380 Volt Electrical Main Power (EMP), (the token simulation circuit exits XOR).

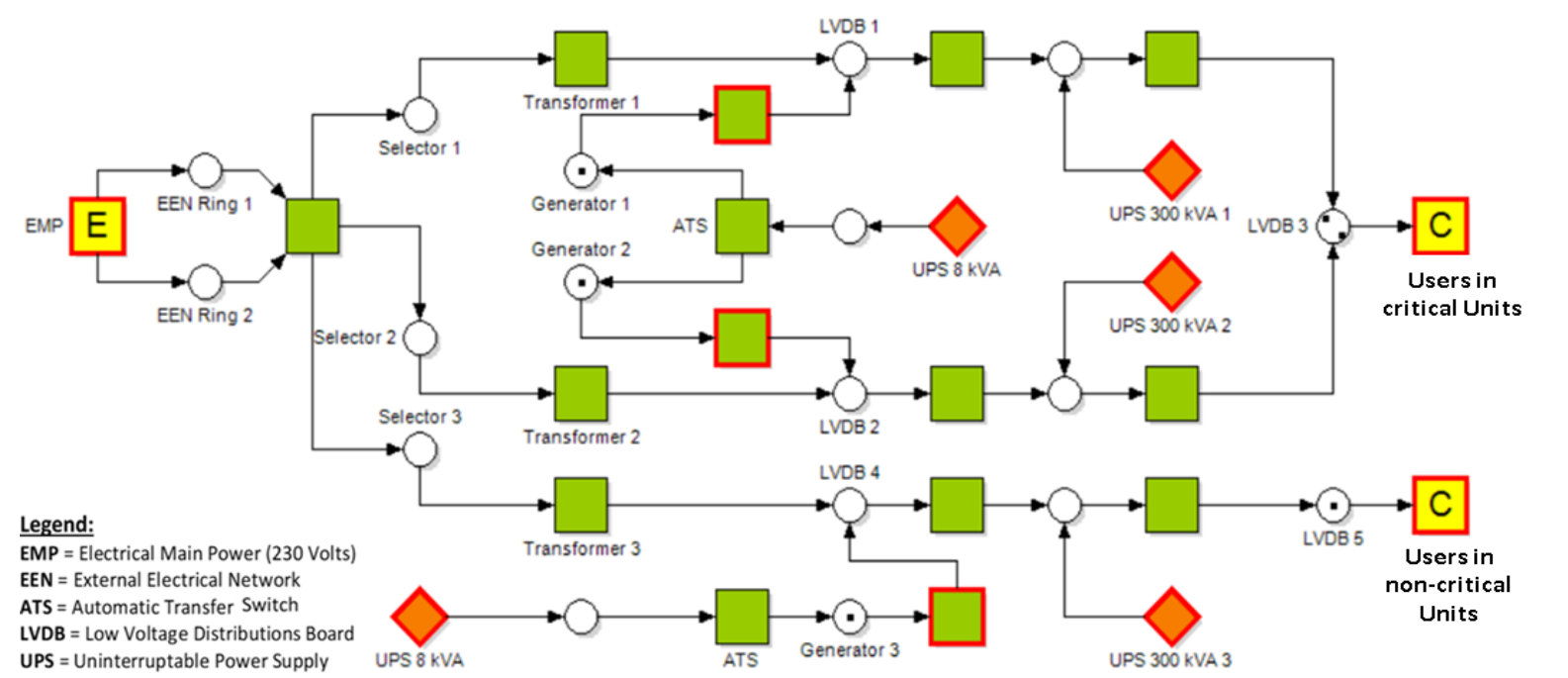


Fig. 13. When the UPS $300 \mathrm{kVA} 1$ \& 2 deliver energy, it happens during 15 to 20 seconds; the ATS (Automatic Transfer switch) will activate Generators and produces tokens from ATS circuit that moves to the positions of generators 1, $2 \& 3$, which means that the Generator will function in place of a non-functioning or extinguished Electrical Main Power (EMP) 380 Volt. (The token simulation circuit exits XORs or UPS 8 kVA).

Figures 11, 12 and 13 show a Petri net that corresponds to a schematic diagram of a series of emergencies hospital electricity system (Figure 9), which are the research targets to ensure the most sensitive and critical equipment, which, it fails, it implies severe problems to the hospital operations. This approach permits to analyse and simulate schematic diagrams that represent the electrical systems through the moving tokens from one place to another, according to the real functioning of the system; easily, it can be identified the sensitive and critical equipment of the hospital emergency electrical circuit. By using Petri Nets simulation, it is ensured that the most critical instrument is the Automatic Transfer System (ATS) that is activated by electronic or computer. The power system has only one ATS installed; then, if a failure occurs, the generators must be activated manually what may imply high risks.

\subsection{Description of the Hospital Electrical System}

This study aims to ascertain and determine whether the electrical installation system in a large hospital, according to the European standards, will be entirely safe, in terms of maintenance. After observing and tracing the whole sequence of events, the questions to answer are the following ones: what is ascertain that is the most critical component or equipment? Does the entire series follow the security standards recommended by the international security standards? The drawing presented in Figure 14, corresponding to the schematic diagrams, describes the electrical sequences that exist in the hospital, according to the above questions, from the block diagram of Figure 7.

It can be seen that Electrical Main Power 380 Volt (EMP) enters through two boards EEN (External Electric Network), rings $1 \& 2$; then, it connects to PS $1 \& 2$ (Power Station), from where it continues to the sectors $1,2 \& 3$ and Transformers $1,2 \& 3$ inboard one. So, it continues through the LVDB 1 \& 2 (Low Voltage Distributions Board), in which it is connected to an ATS (Automatic Transfer switch) as a Genset activator if something fails. Then, the LVDB 1 \& 2 is forward to UPS 1 \& 2 (Uninterruptible Power Supply) of $300 \mathrm{kVA}$. After that, all power sources are delivered through LVDB 3 and continue to the $20 \mathrm{kVA}$ UPS directly to the user. The energy that enters in PS 2 is not widely discussed because it connects loads that are not dangerous. So, the subject in-depth under study is the energy that goes into PS1, that is connected to the critical hospital units; from here we must observe or analyse the essential systems in the electrical hospital's circuits.

To find out if the requirements are observed, one by one, of all functions and malfunctions of the power circuits are analysed, to ensure which are the devices and systems that may cause failures in physical assets' functioning and how to solve them. If the Electrical Mains Power (EMP) of 380 Volt fails, then UPS $300 \mathrm{kVA}$ automatically takes over the function and continues to supply the power to the system; to overcome the danger that occurs within the downtime, the UPS $300 \mathrm{kVA}$ will be replaced by the generators of $1000 \mathrm{kVA}$.

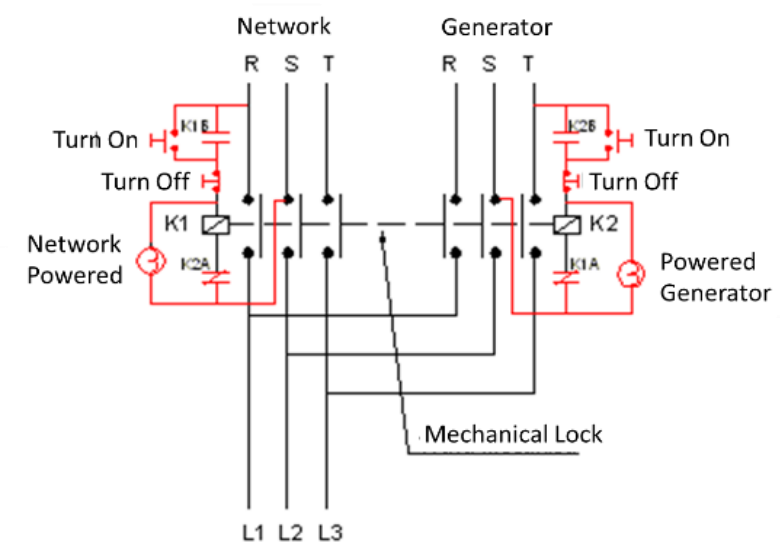

Fig. 14. A T S (Automatic Transfer Switch). 
The ATS manages the generators (Figure 14), i.e., if they do not work, then, the generators must be activated manually, what has a negative impact on the work system and is dependent of the available human resources.
Additionally, in the same order, only one ATS is installed. So, the question arises: how the above circuit responds to an unexpected security system? To answer this question, let us simulate it with the block diagrams shown in Figures 15, 16 and 17.

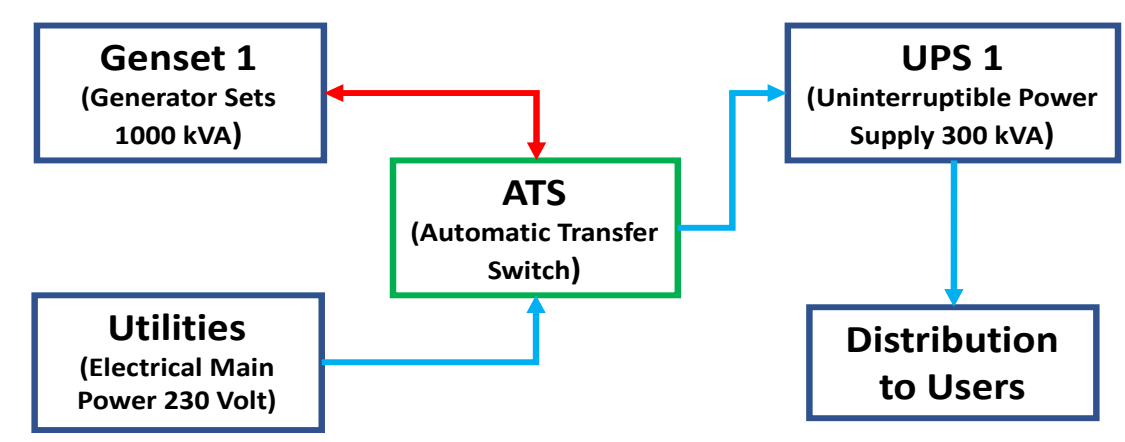

Fig. 15. A Design with an evident weakness, with 1 ATS (Automatic Transfer Switch), 1 Generator and 1 UPS (Uninterrupted Power Supply).

In the block diagram of Figure 15, we emphasise the hypothesis of a break in the current from the main power, when the UPS takes over the primary function. In this situation, the ATS activate Generator replaces the UPS, while is waiting for that main electrical power is on again; unfortunately, if one of the ATS, UPS and Generator fails, then a fatal accident occurs, what permits to infer that this is a very weakness module.

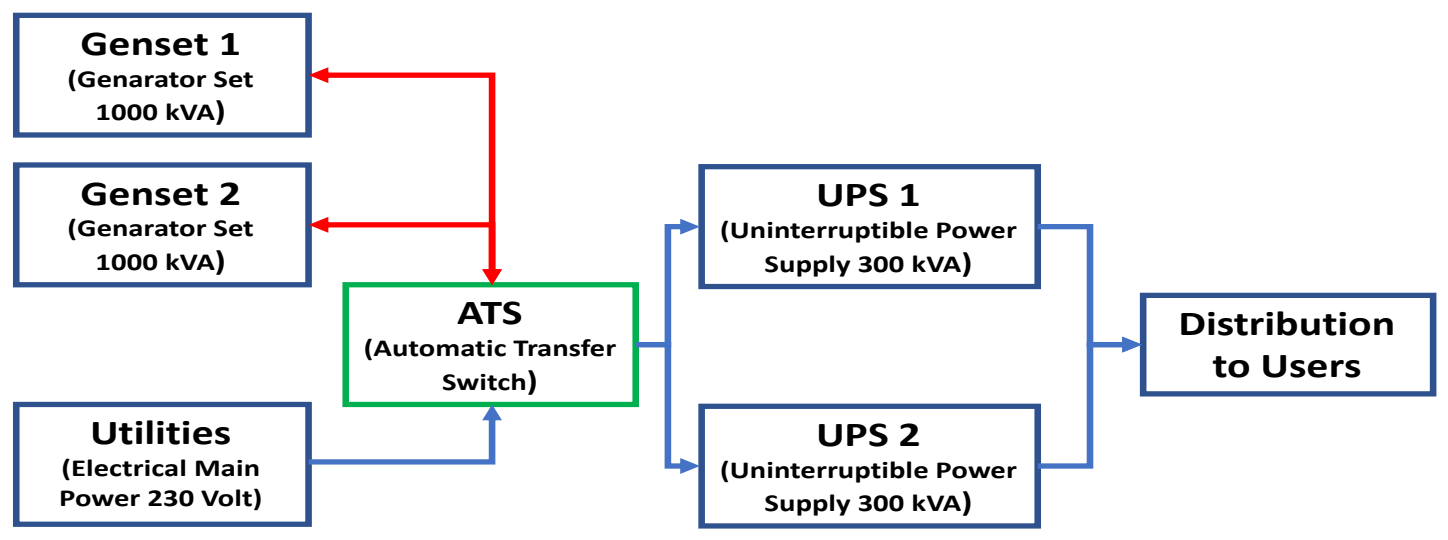

Fig. 16. Weakness module with increased reliability, through 1 ATS (Automatic Transfer Switch), 2 Generators and 2 UPS (Uninterrupted Power Supply).

In the block diagram of Figure 16, if there is a current break from the main power, the UPS $1 \& 2$ will turn on. Then, ATS activates the Gensets $1 \& 2$ to replace the UPS function, while is waiting for that main electrical power is on again; if one of the UPS or Genset fails, then, it will be replaced by another
UPS and Genset. A fatal accident occurs when the ATS fails because there is only one installed; so, this design corresponds a weakness module because it deemed less reliable, what implies to an additional cost of procurement and maintenance. 


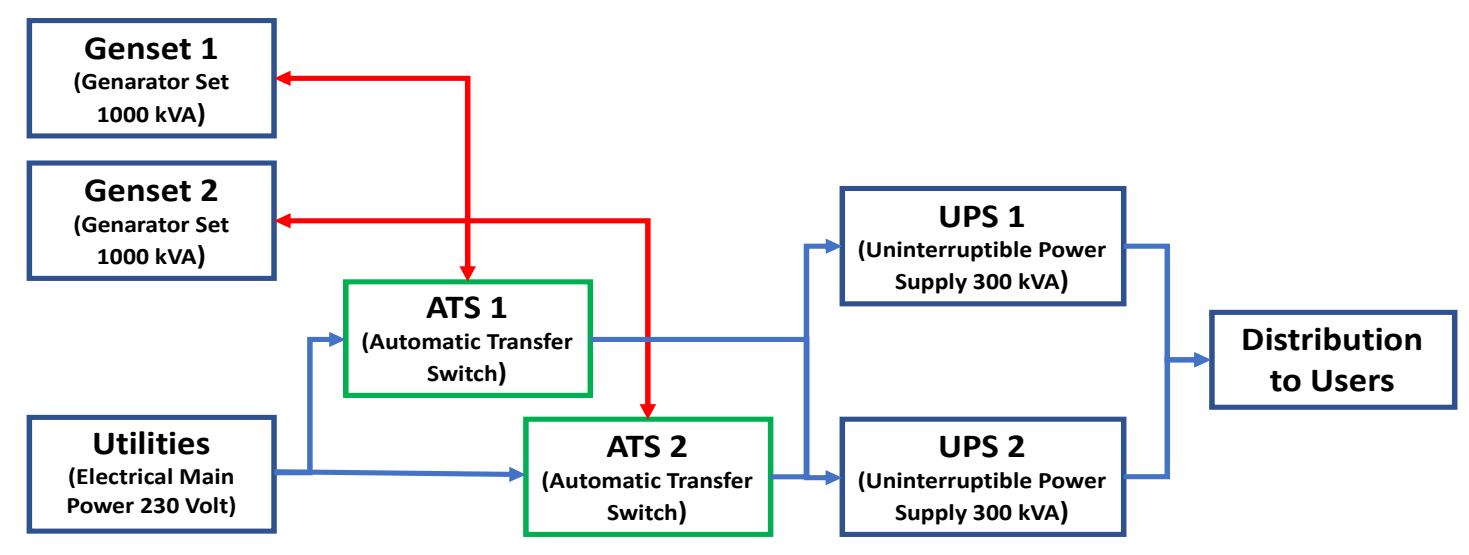

Fig. 17. Improved design - better reliability due to the redundancy, with 2 ATS (Automatic Transfer Switch), 2 Generators and 2 UPS (Uninterrupted Power Supply).

In the block diagram of Figure 17, if there is a current break from the main power, the UPS $1 \& 2$ will turn on. Then, ATS activates the Genset $1 \& 2$ to replace the UPS function, while is waiting for that main electrical power is on again; if one of the UPS, Genset or ATS, fails, then, it will be replaced by
UPS, Genset and other ATS; so, there is no fatality accident occurs, what may be considered a suitable design module, because it is considered to be quite reliable; however, the cost of procurement and maintenance will increase.

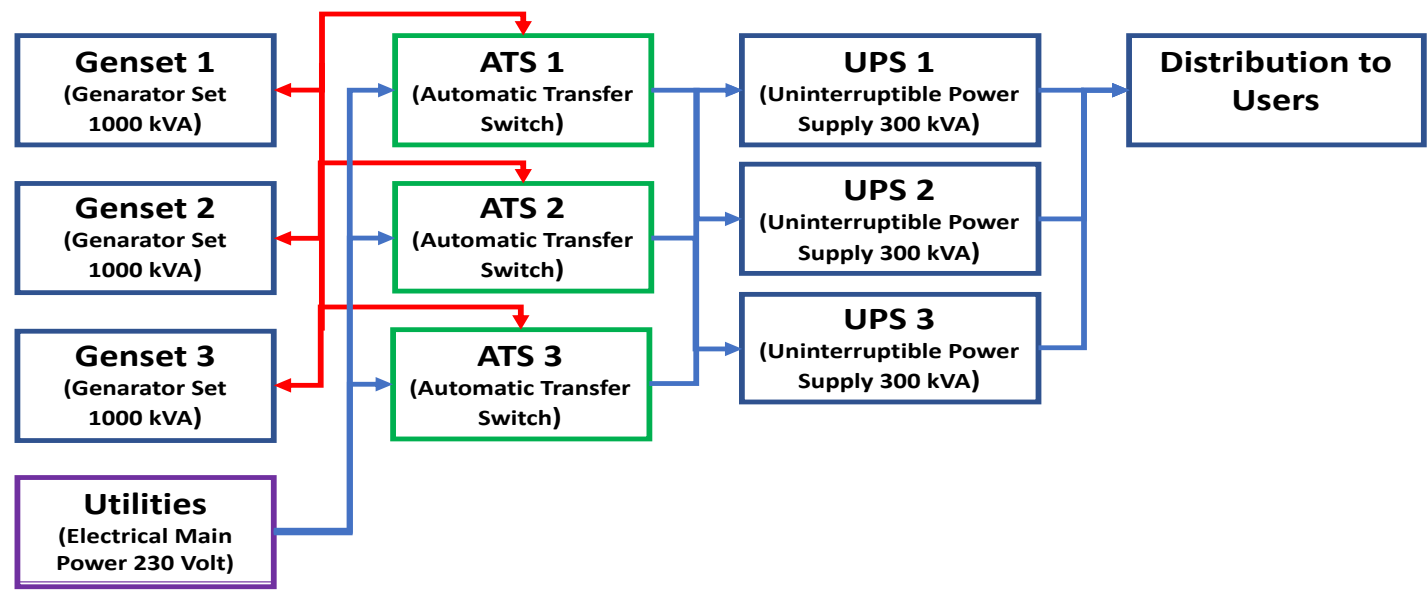

Fig. 18. Increased reliability due to the introduction of another level of redundancy, with 3 ATS (Automatic Transfer Switch), 3 Generators and 3 UPS (Uninterrupted Power Supply).

In the block diagram of Figure 18, if there is a current break from the main power, the UPS 1,2 \& 3 will turn on the main power's functions. Then, ATS activates Genset 1, 2 \& 3, replacing the UPS function, while waits for an intervention from the maintenance team; if one of the UPS, Genset or ATS, fails, then, it will be replaced by the other UPS (Genset and ATS), because there is a redundancy of three units; so, there are no more fatality accidents occur. Then, this design can be considered Good Design because it is considered being very reliable; however, the cost of the system and its maintenance is more expensive, because it needs to install more equipment. After, we analyse all the circuits: it can be concluded that the components of the system are critical to the electrical hospital functioning and the ATS is the most critical item. By consequence, it is discussed and analysed the electrical sequences that must be carefully targeted for research to identify the main functions and failures of each module for the installed load. However, because the hospital does not provide historical data, this is a substantial barrier in this research. Therefore, the next steps of this research will be supported in Fuzzy Petri Nets 
and, when possible, in Stochastic Petri Nets, to continue analysing this type of problems.

\section{Discussion}

The preceding sections presented an approach and result from an analysis of an electric power system in a big European hospital using Petri Nets:

1) Establishing the Asset Hierarchy Block Diagram;

2) Creating the Functional Block Diagram;

3) Creating the Asset Process Flow Diagram;

4) Creating the physical assets Petri Nets modelling;

5) Creating the Asset Process Petri Nets Modelling and Simulations to find the most critical item;

6) Organising the Functions and Operational Failure represented by Block Diagrams.

Based on the preceding, supported by real operation documents, it permits:

1) Identifying the weakest reliability points of the system;

2) Redesigning the system to eliminate the weakest reliability points of the system;

3) Simulating the solutions that best increase the system's reliability and availability;

4) Choosing the best solution for the desired system's reliability.

Based on this research, we can provide all information relating to rigorous strategic management, as is the case of the hospital power supply system, to the maintenance manager. Additionally, we can provide a clear picture to support the decision of how to use the most reliable design according to the resource capabilities and load demand.

However, as was briefly referred to in the preceding section, the electrical power system analysis must be deepened by additional tools, namely by Fuzzy Logic.
One of the most significant advantages of Fuzzy Logic is because it uses human experience and information obtained from the operator. Fuzzy logic, usually, provides solutions that are faster than conventional design techniques.

We believe that, through the assessment of the fewer reliability moduli, it is possible to propose a more reliable design model system, as well its validation through a Fuzzy Logic simulation approach.

\section{Conclusions and Future Developments}

The paper demonstrates the usefulness and pertinence of the Petri Nets in the modelling and analysing of the Electrical Power Supply System in a big European hospital, which can be generalised to any other organisation, regardless of its nature. The paper also demonstrates as the Petri Nets can help to identify the weaknesses of a complex electrical system and to simulate more reliable solutions and how to validate them. The paper emphasises the importance of Petri Nets as a powerful tool in the area of maintenance management, providing analysis and simulation of the systems to increase the reliability and availability of the individual assets and their operations.

However, from this paper, a lot of questions have appeared, namely about new designs of the electrical power systems and how to implement them.

The Fuzzy Logic may be one powerful tool to evaluate new designs because it uses human experience and information obtained from the operator.

By consequence, future developments ought to be supported on Fuzzy Petri Nets and, when possible, in Stochastic Petri Nets, if historical fault data is available. 


\section{References}

[1] American Hospital Association (AHA), (1980): Hospital engineering handbook. Third Edition, Chicago, Illinois 60611, U.S.A. ISBN 0-87258311-2.

[2] Anderson, Ronald, T., \& Neri Lewis, (1990): Reliability Centered Maintenance Management and Engineering Methods. Elsevier Science Publishing Co., INC. 655 Avenue of Americas, New York, NY 10010, USA. ISBN 1-85166-470$\mathrm{X}$.

[3] Department of the Army, TM 5-698-2, (2003)

Reliability-Centered Maintenance (RCM) for Command, Control, Communications, Computer, Intelligence, Surveillance, and Reconnaissance (C4ISR) Facilities, HEADQUARTERS DEPARTMENT OF THE ARMY Washington, DC.

https://www.wbdg.org/FFC/ARMYCOE/COETM/ tm_5_698_2.pdf.

[4] Farinha, J. (2018). Asset maintenance engineering methodologies. Boca Raton, FL: CRC Press/Taylor \& Francis Group, USA. ISBNs: 1351869337 and ISBNs: 9781351869331.

[5] Gulati, Ramesh (2008): Maintenance and Reliability Best Practices. Industrial Press, Inc., New York USA. ISBN 978-0-8311-3311-5.

[6] Mourbay, John (1992): Reliability Centered Maintenance (RCM II). Second Edition, Industrial Press, Inc., New York USA. ISBN 978-0-83113311-3.

[7] Wang, Wenbin (2012): "An overview of the recent advances in delay-time-based maintenance modelling". DOI: 10.1016/j.ress.2012.04.004.

[8] Adekitan, A. I., Bukola, A., \& Kennedy, O. (2018). A data-based investigation of vehicle maintenance cost components using ANN. IOP Conference Series: Materials Science and Engineering, 413, 012009. https://doi.org/10.1088/1757-899x/413/1/012009

[9] Dewi, S., Latief, Y., \& Machfudiyanto, R. A. (2020). Optimizing maintenance of electrical components with BIM and web-based inputs to improve safety performance in government green building. IOP Conference Series: Materials Science and Engineering, 830, 022033. https://doi.org/10.1088/1757-899x/830/2/022033
[10]Fatimah, A., \& Amin, J. (2019). Evaluation of maintenance system in emergency installation of Meuraxa Hospital Banda Aceh, Indonesia. IOP Conference Series: Materials Science and Engineering, 674, 012027. https://doi.org/10.1088/1757-899x/674/1/012027

[11] Indriani, I., Latief, Y., \& Machfudiyanto, R. A. (2020). Development of green building maintenance information system for electrical components based on ministerial regulation. IOP Conference Series: Materials Science and Engineering, 830, 022050.

https://doi.org/10.1088/1757-899x/830/2/022050

[12] Afzali, P., Keynia, F., \& Rashidinejad, M. (2019). A new model for reliability-centered maintenance prioritisation of distribution feeders. Energy, 171, 701-709. https://doi.org/10.1016/j.energy.2019.01.040

[13] Hoseini, N., Sheikholeslami, A., Barforoushi, T., \& Latify, M. A. (2020). Preventive maintenance mid-term scheduling of resources in multi-carrier energy systems. Energy, 197, 117164. https://doi.org/10.1016/j.energy.2020.117164

[14] Mwanza, Bupe, G., Mbohwa, Charles, (2015): “An assessment of the effectiveness of equipment maintenance practices in public hospitals". DOI: 10.1016/j.promfg.2015.11.045.

[15] The "IEEE C2: National Electrical Safety Code, 2007". ISBN 0-7381-4893-8.

[16] Christiansen, N., Kaltschmitt, M., \& Dzukowski, F. (2016). Electrical energy consumption and utilization time analysis of hospital departments and large-scale medical equipment. Energy and Buildings, 131, 172-183. https://doi.org/10.1016/j.enbuild.2016.09.023

[17]BenSaleh, Mohammed and Hennache, Ali, (2010): "Planning, Optimizing and Analyzing of Safety and Maintenance for the Critical Role of Emergency Power Plant in Saudi Healthcare Facilities". DOI: 10.1109/SIBERCON.201.555378.

[18] Jamshidi, et al. (2015) "A comprehensive fuzzy risk-based maintenance framework for prioritisation of medical devices". DOI: 10.1016/j.asoc.2015.03.054.

[19] The WHO (World Health Organization and Pan American Health Organization), (2015). ISBN 978 9241548984. 
[20] Abdul, et al. (2015)" A risk-based shutdown inspection and maintenance interval estimation considering human error". DOI: 10.1016/j.psep.2015.11.011.

[21] Ikuzwe, A., Xia, X., \& Ye, X. (2020). Maintenance optimization incorporating lumen degradation failure for energy-efficient lighting retrofit projects. Applied Energy, 267, 115003. https://doi.org/10.1016/j.apenergy.2020.115003

[22] Carnero, M. C., \& Gómez, A. (2017). Maintenance strategy selection in electric power distribution systems. Energy, 129, 255-272. https://doi.org/10.1016/j.energy.2017.04.100

[23] Christiansen, Nils (2015) "Electricity consumption of medical plug loads in hospital laboratories. Identification, evaluation, prediction and verification" DOI: 10.1016/j.enbuild.2015.08.022.

[24] Swain, K. P., \& De, M. (2019). A novel electrical proximity index for voltage control in smart distribution system. Electric Power Systems Research, 172, 50-62. https://doi.org/10.1016/j.epsr.2019.03.006

[25] Chan, A. P. C., Wong, F. K. W., Hon, C. K. H., \& Choi, T. N. Y. (2020). Construction of a Bayesian network model for improving the safety performance of electrical and mechanical (E\&M) works in repair, maintenance, alteration and addition (RMAA) projects. Safety Science, 131, 104893. https://doi.org/10.1016/j.ssci.2020.104893

[26] Kallambettu, J., \& Viswanathan, V. (2018). Application of functional safety to electrical power equipment and systems in process industries. Journal of Loss Prevention in the Process Industries, 56, 155-161. https://doi.org/10.1016/j.jlp.2018.07.009

[27] García-Sanz-Calcedo, J., \& Gómez-Chaparro, M. (2017). Quantitative analysis of the impact of maintenance management on the energy consumption of a hospital in Extremadura (Spain). Sustainable Cities and Society, 30, 217-222. https://doi.org/10.1016/j.scs.2017.01.019

[28] García-Sanz-Calcedo, J., Gómez-Chaparro, M., \& Sanchez-Barroso, G. (2019). Electrical and thermal energy in private hospitals: Consumption indicators focused on healthcare activity. Sustainable Cities and Society, 47, 101482. https://doi.org/10.1016/j.scs.2019.101482

[29] Ismail, A. G., El-Dabah, M. A., \& Nassar, I. A. (2020). Enhancement of Electrical Distribution Networks Performance Using the Load Management Methodology. Energy Reports, 6,
2066-2074.

https://doi.org/10.1016/j.egyr.2020.07.018

[30] Yousefli, Z., Nasiri, F., \& Moselhi, O. (2020).

Maintenance workflow management in hospitals:

An automated multi-agent facility management

system. Journal of Building Engineering, 32, 101431.

https://doi.org/10.1016/j.jobe.2020.101431

[31] Yuan, Q. (2020). Research on Condition Analysis of Secondary Equipment Based on Electrical Automation Technology. IOP Conference Series: Earth and Environmental Science, 440, 032100. https://doi.org/10.1088/1755-1315/440/3/032100

[32] Poppe, J., Boute, R. N., \& Lambrecht, M. R. (2018). A hybrid condition-based maintenance policy for continuously monitored components with two degradation thresholds. European Journal of Operational Research, 268(2), 515-532. https://doi.org/10.1016/j.ejor.2018.01.039

[33] Svigelj, Ales (2018) Pseudo measurements based on smart meters prosumer's characterization for distribution system state estimation, INTERNATIONAL JOURNAL OF CIRCUITS, SYSTEMS AND SIGNAL PROCESSING Volume 12, 2018

[34]N. S. Sandhu, S.Chanana (2018) Comparative Analysis of Conventional and Multi-Rotor Wind Turbines, INTERNATIONAL JOURNAL OF CIRCUITS, SYSTEMS AND SIGNAL PROCESSING Volume 12, 2018.

[35] ALES SVIGELJ (2018) Prosumer's Characterization Based Pseudo Measurements for Distribution System State Estimation, Department of Communication Systems Jozef Stefan Institute Jamova cesta 39, Ljubljana SLOVENIA ales.svigelj@ijs.si https://www.ijs.si/

[36] Wang, Jiacum, (1998): “Time Petri Nets Theory and Application" Springer Science + Business Media New York. ISBN 978-1-4613-7531-9.

[37] Volovoi, V., (2003): "Modelling of system reliability Petri nets with ageing tokens". DOI: 10.1016/j.ress.2003.10.013.

[38] Chew, S.P., et al. (2007): "Phased mission modelling of systems with maintenance-free operating periods using simulated Petri nets". https://dspace.lboro.ac.uk/2134/3836. It accessed on January 06, 2017.

[39] Garg, Harish, (2012): "Reliability analysis of repairable systems using Petri nets and vague Lambda Tau methodology". DOI: 10.1016/j.isatra.2012.06.009. 
[40]Leigh, J.M., et al. (2014): "Use of Petri nets to model the maintenance of wind turbines". DOI: 10.1002/qre.1737.

[41] Ren, Zhanyong, at.al. (2014): "Modelling the Performance of Aircraft Utilizing Maintenance Free Operating Periods". DOI: 10.1016/j.proeng.2014.12.528.

[42] Sadou, Nabil, et al. (2009): "Reliability analysis of discrete event dynamic systems with Petri nets". DOI: 10.1016/j.ress.2009.06.006.

[43] Sheng, J., \& Prescott, D. (2019). A coloured Petri net framework for modelling aircraft fleet maintenance. Reliability Engineering \& System Safety, 189, 67-88. https://doi.org/10.1016/j.ress.2019.04.004

[44]BAIDADA, C., BOUZIANE, E. M., \& JAKIMI, A. (2019). A New Approach for Recovering HighLevel Sequence Diagrams from Object-Oriented Applications Using Petri Nets. Procedia Computer Science, 148, 323-332.

https://doi.org/10.1016/j.procs.2019.01.040

[45]Xie, N., Duan, M., Chinnam, R. B., Li, A., \& Xue, W. (2016). An energy modeling and evaluation approach for machine tools using generalized stochastic Petri Nets. Journal of Cleaner Production, 113, 523-531. https://doi.org/10.1016/j.jclepro.2015.09.100

[46]Lee, J., \& Mitici, M. (2020). An integrated assessment of safety and efficiency of aircraft maintenance strategies using agent-based modelling and stochastic Petri nets. Reliability Engineering \& System Safety, 202, 107052. https://doi.org/10.1016/j.ress.2020.107052

[47]Kabir, S., \& Papadopoulos, Y. (2019). Applications of Bayesian networks and Petri nets in safety, reliability, and risk assessments: A review. Safety Science, 115, 154-175. https://doi.org/10.1016/j.ssci.2019.02.009

[48] Caterino, M., Fera, M., Macchiaroli, R., \& Lambiase, A. (2018). Appraisal of a New Safety Assessment Method using the Petri Nets for the Machines Safety. IFAC-PapersOnLine, 51(11), 933-938. https://doi.org/10.1016/j.ifacol.2018.08.48

[49] Eisenberger, D., \& Fink, O. (2017). Assessment of maintenance strategies for railway vehicles using Petri-nets. Transportation Research Procedia, 27, 205-214. https://doi.org/10.1016/j.trpro.2017.12.012

[50] Taleb-Berrouane, M., Khan, F., \& Amyotte, P. (2020). Bayesian Stochastic Petri Nets (BSPN) - A new modelling tool for dynamic safety and reliability analysis. Reliability Engineering \& System Safety, 193, 106587. https://doi.org/10.1016/j.ress.2019.106587

[51]Zhou, J., \& Reniers, G. (2020). Modelling and application of risk assessment considering veto factors using fuzzy Petri nets. Journal of Loss Prevention in the Process Industries, 67, 104216. https://doi.org/10.1016/j.jlp.2020.104216

[52]Fierro, L. H., Cano, R. E., \& García, J. I. (2020). Modelling of a multi-agent supply chain management system using Colored Petri Nets. Procedia Manufacturing, 42, 288-295. https://doi.org/10.1016/j.promfg.2020.02.095

[53]Elusakin, T., \& Shafiee, M. (2020). Reliability analysis of subsea blowout preventers with condition-based maintenance using stochastic Petri nets. Journal of Loss Prevention in the Process Industries, 63, 104026.

https://doi.org/10.1016/j.jlp.2019.104026

[54]Liu, L., Liu, X., \& Liu, G. (2018). The risk management of perishable supply chain based on coloured Petri Net modelling. Information Processing in Agriculture, 5(1), 47-59. https://doi.org/10.1016/j.inpa.2017.12.001

[55] Sheng, J., \& Prescott, D. (2019). Using a novel hierarchical coloured Petri net to model and optimise fleet spare inventory, cannibalisation and preventive maintenance. Reliability Engineering \& System Safety, 191, 106579. https://doi.org/10.1016/j.ress.2019.106579

[56] Singh, P., \& Singh, L. (2019). Verification of safety critical and control systems of Nuclear Power Plants using Petri nets. Annals of Nuclear Energy, 132, 584-592. https://doi.org/10.1016/j.anucene.2019.06.0

[57]Farinha, José, (2011): Manutenção A Terologia e as Novas Ferramentas de Gestão. 1 ${ }^{\mathrm{a}}$. Edição, Monitor, Lda. Lisboa, Portugal. ISBN: 9789729413827.

[58] Solaiman, R. S., Kherbek, T. G., \& Ahmad, A. S. (2020, March). A Fuzzy Petri Net Model Adapts to Changing Operating Conditions to Improve Power Systems Fault Prognosis. 2020 International Youth Conference on Radio Electronics, Electrical and Power Engineering (REEPE). 2020 International Youth Conference on Radio Electronics, Electrical and Power Engineering (REEPE). https://doi.org/10.1109/reepe49198.2020.9059243 
[59] http://www.yasper.org/downloads/Yasper_User_G uide.pdf. It accessed on October 06, 2019.

[60] van Hee, K., Oanea, O., Post, R., Somers, L., \& van der Werf, J. M. (n.d.). Yasper: a tool for workflow modelling and analysis. Sixth International Conference on Application of Concurrency to System Design (ACSD’06). Sixth International Conference on Application of Concurrency to System Design (ACSD'06). https://doi.org/10.1109/acsd.2006.37

[61] Sulaiman, H., Othman, M., Othman, M., Rahim, Y. \& Pee, N. (2014). Advanced computer and communication engineering technology: proceedings of the 1st International Conference on Communication and Computer Engineering. Berlin: Springer.

[62] Jensen, Kurt, (1991): High-level Petri nets: theory and application. Computer Science Department Aarhus University, Ny Munkegade, Bldg. 540 DK8000 Aarhus C, Denmark. e-ISBN-13:978-3-64284524-6.

\section{Creative Commons Attribution License 4.0 (Attribution 4.0 International, CC BY 4.0)}

This article is published under the terms of the Creative Commons Attribution License 4.0

https://creativecommons.org/licenses/by/4.0/deed.en_US 